contains a definite quantity of a mercuric salt. The advantage of this lubricant is that it remains sterile, even when exposed for several days to the air, and of course natheters and probes which have been lubricated with it remain sterile also. It is said to be non-irritating and to arrest the growth of germs in the urinary tract. Catheterpurin is soluble in water and therefore does not interfere with cystoscopic observation.

\section{"TABLOID" HYPODERMIC TRINITRIN.}

(Bdrroughs, Weixcome, and Co., SNow ilmli Butldings, LONDON, E.C.)

The convenience of being able to carry in the pocket, so to speak, exact doses of the powerful drug trinitrin is obvious. Its restorative effects in aortic disease and in angina pectoris are well known. The tabloid hypodermic trinitrin contains ${ }_{1}^{1} \frac{1}{0}$ th of a grain of the drug, but tabloids may be obtained containing $\frac{1}{5} \pi$ th of a grain, $\frac{1}{2} 00$ th of a grain, and $\frac{1}{2} \frac{1}{5}$ th of a grain respectively, while the tabloid trinitrin compound contains in addition to $\frac{1}{10} \frac{1}{0}$ th of a grain of trinitrin capsicin and menthol.

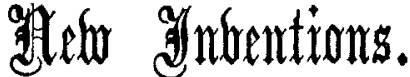

\section{AN IMPROVED VACCINATOR.}

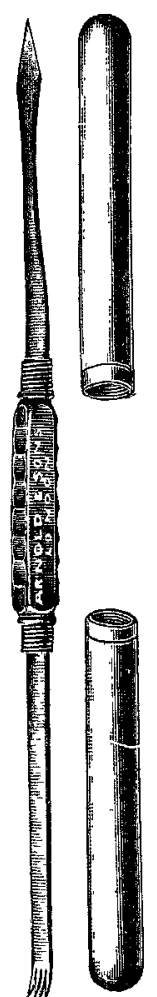

THE illustration represents a vaccinator which Messrs. Arnold and Sons of West Smithfield, London, E.C , have made at my suggestion and which, I think, embodies some slight improvements on those at present in use. Its principal features may be enumerated as follows:-(1) It combines in one instrument a lancet and a scarifier; (2) the ends are kfpt clean by screw.on covers of distinctive sizes so that the instrument can be easily carried either in the pocket or in the vaccinating case ; (3) being of larger size than the vaccinators generally made it is more convenient, especially as the grip is fluted; (4) the body or centre is not only square, which prevents the instrument from rolling about, but is of such a size that the ends are prevented from touching the surface on which it is placed; (5) the scarifier being bent at a considerable angle enables the back of it to be used for rubbing in the lymph; (6) there is in each blade a small hole intended for use when breaking off the ends of the vaccine tube; and (7) being forged from a single piece of metal it can easily be sterilised.

Southampton.

A. A. Mackeith.

\section{PELVIC PEDICLE NEEDLES WITH RING LEVER HANDLES.}

THE long-handled pelvic pedicle needle, though it still survires, presents several objectionable features which place it in the same category as the heavy-jawed forceps formerly considered essential for pelvic surgery. Not only is its point difficult to control but its long handle is continually getting in the way and interfering with the free movement of the point of the needle. On the other hand, loose needles gripped in holders, the best type of which is Bonney's, are never entirely free from a tendency to slip, nor can the driving force be applied directly behind the point of the needle. The needles shown in the illustration have been made for me by Messrs. Mayer and Meltzer of Great Portland-street, London, W. Each needle has practically two handles, one of which is grasped during the stabbing or pushing movement which takes up the tissues (Fig. 1), while the other, aided by a lever action on the first ring, serves to make the point of the needle present in the abdominal wound to be threaded or unthreaded (Fig. 2). The grip is convenient, the force is applied directly behind the point, control is perfect, and the ring-handle is so small that it is never in the

FIG. 1.

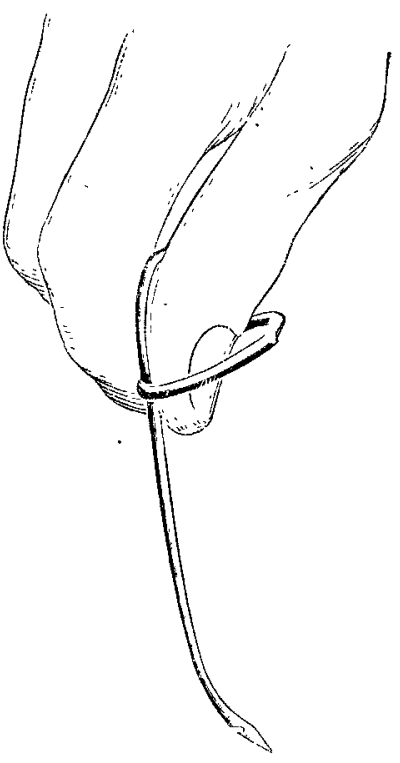

way. I have found the needles especially handy in dealing with the stump in hysterectomy and in ovariotomy, and in cystotomy to pass the guide-sutures through the bladderwall, but there are few abdominal operations in which they

FIG. 2.

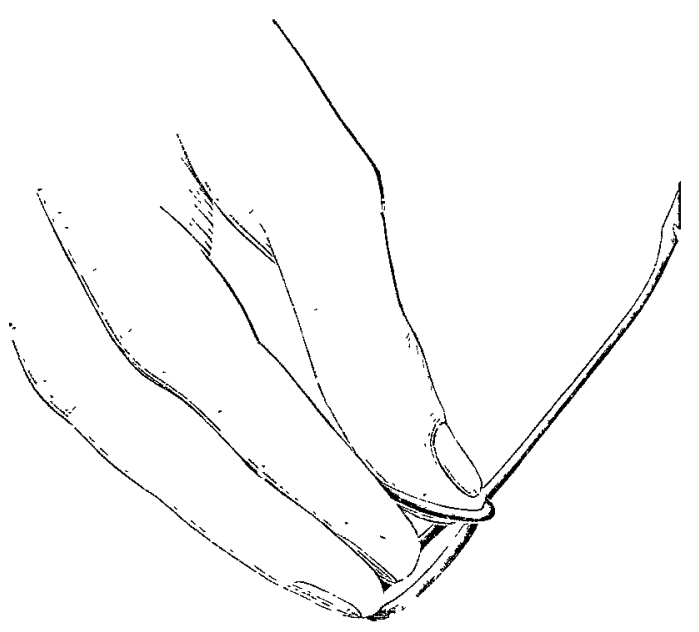

may not be found convenient. The short, nearly straight pattern (Fig. 3) is the most generally useful and the slot type is preferable to an eyed needle if a deft assistant is available to thread the needle after it has been passed

FIG. 3.
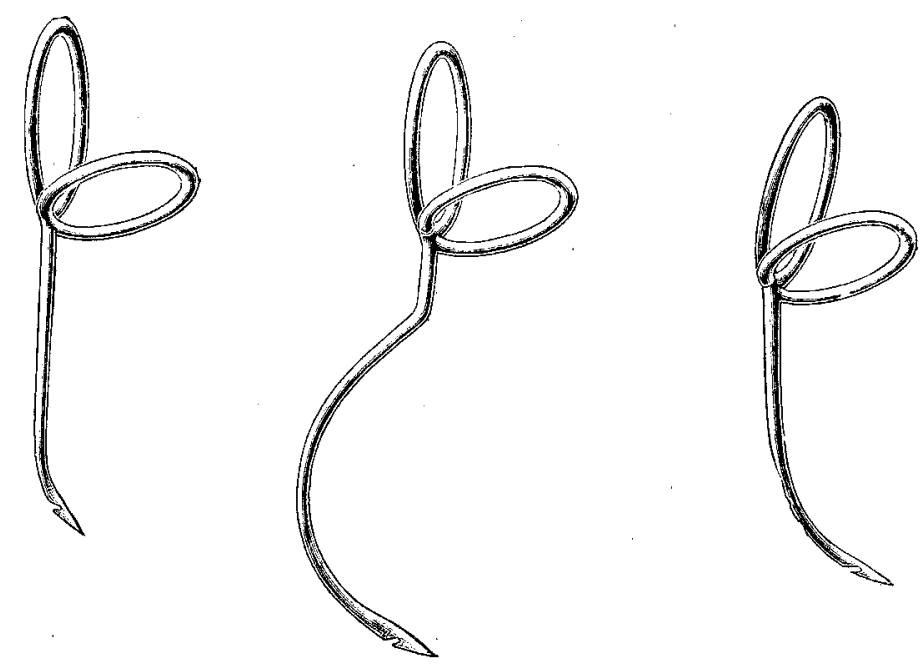

through the tissues of the pedicle and made to present in the wound.

Wimpole-street, $\mathrm{w}$.
W. Sampson Handel- 


\section{THE LANCET.}

LONDON: SATURDAY, OCTOBER 2O, 1906.

\section{Universities and Medical Education.}

Is an eloquent and suggestive address delivered by Sir JAMES CRICHTon-Browne at the opening of the Medical Department of the University of Leeds on Oct. 1st some points of very general interest and of far-reaching import. ance were brought forw ird in regard to the value of the university standard of education to the community at large, especially in respect of the training of medical men. Sir JiMes Crichton-Browne pointed out that any university which endeavours to adjust its teaching and its functions in any degree to the growing and changing requirements of the community for whose benefit it is intended must adapt itself to those requirements by enlarging its curriculum and by concerning itself intimately with the life around it. He further maintained that while great and epoch.marking advances were usually made by exceptional men of originality and imaginative power, whose force of intellect must assert itself no matter how adverse were their circumstances, there were always men of ability, capable of admirable worl in science and industry, whose gifts required education and encouragement, and for such men university training and technical education are essential. That the lack of such opportunities may be little short of a national calamity was illustrated by a reference to the loss of the coal-tar industries which rightly belonged to this country, since the foundation was laid by the discoveries of Sir WILliam H. Perkin, of which the fiftieth anniversary has recently been celebrated. To quote from the address: "We had the raw material, we had the capital, we had the skilled labour, but we allowed the profitable trade in dyes, perfumes, and drugs, which is now said to be worth fifty millions per annum, to go to Germany, simply because we had not at the time the educational machinery to carry out the experimental research necessary to enable us to take advantage of our own discoveries. We were short of investigators, of leaders, of captains of science and industry in those days, and of the true spirit of scientific enterprise, and we are still short of them." It is these phases of university work which it is at the present time most important to encourage, for the application of scientific methods to manufactures and to matters of everyday importance is a vital necessity, and this can only be effected if encouragement is given to suitable men to devote themselves to research. Sir JaMES Crichton-Browne does not share the gloomy forebodings of pessimists with regard to the future of our country, but admits that while Germany has encouraged research by Government aid in the organisation and equipment of laboratories and in the careful selection of teachers, lecturers, professors, and investigators, England has been remiss in promoting those interests which require scientific and medical research. Again, in German universities the teaching staif is much larger in proportion to the number of students than in those of this country. To these factors the recent rapid advances made by Germany in medicine and technology must be largely attributed.

In regard to medical education and research in this country there is, perhaps, almost a greater neglect or indifference on the part of the public generally than of any other branch of applied science, and in this connexion the remarks of Sir JAMES CRICHTON-BRO WNE are particularly noteworthy. He regards this neglect or indifference as astonishing when the importance to the general welfare of the adequate instruction of medical men is considered. He points out that in no other of the great professions has less been done by the State or by private philanthropy to supplement the payments of those seeking to enter it ; indeed, that in many instances medical schools have been developed and supported exclusively by medical men and medical students. Owing to the increased length of the curriculum and the constantly increasing cost of equipment and maintenance of the various departments necessary to a complete medical school, those institutions which are not endowed are at, or near, breaking strain and it is difficult to see any other solution of the problem than assistance "either from the State chest or by overflow from plethoric private coffers." Some figures quoted in the address are notew orthy as illustrating the view taken of these matters in other countries; in Zürich, for example, a few years ago the medical department of the university received in addition to the fees of the students, then 245 in number, a yearly grant of $£ 4500$ from the canton which, moreover, built and maintained the buildings. This instance, in a small country, without the great resources and wealth of our own, should stimulate a like generosity in regard to our own institutions. But it is not only medical education but investigation and research in medicine and its ancillary sciences which require encouragement and pecuniary aid if we are to retain that position which we have hitherto held and of which we as a profession are justly proud. It is in research work that Germany is advancing and in which we must endeavour to overtake her, and this, Sir JAMES CRICHTON-BRownE stoutly maintains, we can do if given the means, for, with all her advantages, we have no cause to shrink from comparison with her in medical science, while he is of opinion that our young English practitioner is quite equal, if not superior, to any continental compeer.

The remainder of this interesting address is largely devoted to demonstrating the importance of the wide scope of a university training, which should have larger aims than material advancement or commercial prosperity, for it must foster culture, encourage individuality, indeed, be universal in its range. In regard to those studying medicine, it is important that the outlook should be as broad as possible in order to counteract the "inevitably materialistic tendency" of the actual medical studies, and in this connexion Sir James Crichton-Browne gives a detailed criticism of the materialistic and neo-materialistic explanations of 